\title{
Nüks varikosel tedavisinde mikrocerrahi varikoselektomi
}

\author{
Microsurgical varicocelectomy for treatment of recurrent varicocele
}

\author{
Ahmet Gökçe1, H. Can Direk¹, Anıl Erdik
}

\section{öz}

AMAC:: Varikosel, infertilite nedeni ile üroloji kliniğine başvuran erkeklerde en sık gözlenen düzeltilebilir patolojilerdendir. Varikosel cerrahisi sonrası görülen en sık komplikasyonlardan birisi de varikoselin nüksetmesidir.

GEREÇ VE YÖNTEM: Bu çalışmada, kliniğimizde Kasım 2014 - Mayıs 2017 tarihleri arasında nüks varikosel nedeniyle mikrocerrahi varikoselektomi (NMCV) yapılan hastaların verileri ile, ilk defa tanı konulmus ve primer MCV (PMCV) yapılan hastaların verilerinin retrospektif olarak karşılaştırılması amaçlanmıştır. Çalışmaya sol Grade 3 varikosel nedeniyle subinguinal PMCV veya NMCV yapılan hastaların verileri dahil edildi. Hastaların yaş, ameliyat öncesi ve sonrası semen analizleri, komplikasyon oranları karşılaştıııldı.

BULGULAR: Calıșmaya alınan hastaların yas ortalaması PMCV grubunda 30 (22-48) iken NMCV grubunda 31,2 (25-42) idi ( $>0,05)$. Primer ve nüks gruptaki operasyon öncesi semen parametreleri karşılaştırıldığında değerler arasında istatistiksel olarak anlamlı bir fark bulunmadı. PMCV yapılan hastaların operasyon öncesi ve sonrası semen parametreleri değerlendirildiğinde volüm ve morfoloji açısından anlamlı bir fark olmadığı, konsantrasyon ve motilite açısından istatistiksel olarak anlamlı iyileşme olduğu gözlendi. NMCV yapılan hastaların operasyon öncesi ve sonrası semen parametreleri değerlendirildiğinde ise volüm, konsantrasyon ve morfoloji açısından anlamlı bir fark olmadığı, motilite açısından istatistiksel olarak anlamlı bir iyileşme olduğu gözlendi. Hastalar komplikasyon açısından değerlendirildiğinde, ameliyatlar sonrasında her iki grupta da herhangi bir komplikasyonun gelişmediği gözlendi.

SONUÇ: Varikosel tedavisinde en düşük nüks oranına sahip yöntem olan mikrocerrahi varikoselektomi, nüks varikosel cerrahisinde de altın standart yöntem olabilir.

Anahtar Kelimeler: varikosel; mikrocerrahi; subinguinal varikoselektomi; rekürrens

\section{ABSTRACT}

OBJECTIVES: Varicocele is the most common remediable pathology in men who are referred to the urology clinic for infertility. One of the most common complications after varicocele surgery is recurrence.

MATERIAL AND METHODS: The aim of this retrospective study was to compare the data of patients who underwent microsurgical varicocelectomy for recurrent varicocele (RMSV) and patients who were diagnosed for the first time and underwent primary MSV (PMSV) in our clinic between November 2014 and May 2017. Patients receiving subinguinal PMCV or NMCV due to left Grade 3 varicocele were included in the study. Patient age, preoperative and postoperative semen analysis, and complication rates were compared.

RESULTS: The mean age of the study subjects was $30(22-48)$ and 31.2 (25-42) years in the PMSV and RMSV groups respectively $(\mathrm{p}>0.05)$. There was no statistically significant difference in preoperative semen analysis between primary and recurrent group. When the sperm parameters of PMSV patients were evaluated before and after operation, there was no statistically significant difference in terms of volume and morphology, and there was statistically significant improvement in terms of concentration and motility. There were no statistically significant differences in terms of volume, concentration and morphology and statistically significant improvement in motility before and after the operation in RMSV group. No complications were observed in both groups after the operations.

CONCLUSION: Microsurgical varicocelectomy, the method which has the lowest recurrence rate in varicocele treatment, may be the gold standard in recurrent varicocele surgery.

Keywords: varicocele; microsurgery; subinguinal varicocelectomy; recurrence

\section{GíRiș}

Varikosel, infertilite nedeni ile üroloji kliniğine başvuran erkeklerde en sık gözlenen düzeltilebilir patolojilerdendir. ${ }^{[1]}$ Normal popülasyonda \%10-15 arasında gözlenirken, bu oran primer infertilite ile başvuran erkeklerde $\% 40$, sekonder infertilitede ise $\% 80$ 'lere kadar yükselebilmektedir. ${ }^{[2]}$ Varikosel; sperm sayısı, hareket ve morfolojide bozulma, testis volümünde azalma ve Leydig hücre disfonksiyonu gibi istenmeyen durumlara yol açarak infertiliteye sebep olur. ${ }^{[3]}$ İnfertilite nedeniyle başvuran erkek 
hastada fizik muayene ile varikosel saptandığında ya da radyolojik yöntemlerle tanı konulduğunda, hastanın sperm değerlerinde bir ya da birden fazla parametrede bozulma varsa ve hastanın eşinde infertiliteye sebep olabilecek başka bir patoloji söz konusu değilse, hasta tedavi edilmelidir. ${ }^{[3,4]}$ Varikosel tedavisi, radyolojik, laparoskopik veya açık cerrahi yöntemlerle yapılabilir. Varikosel cerrahisi sonrası en sık görülen komplikasyonlardan birisi varikosel nüksüdür. Varikosel nüksünün ana nedenleri olarak, operasyon esnasında etkisiz venöz ligasyon ve anatomik varyantlar bildirilmiştir. ${ }^{[5]}$ Bazı araştırmacılar da kollateral reflünün nükse neden olduğunu savunmaktadır. ${ }^{[6,7]}$

Nüks oranı cerrahi tekniğe bağlı olarak değişmektedir (Tablo 1). ${ }^{\left[{ }^{[]}\right.}$Nüks oranları yüksek ligasyonda \%29'lara kadar çıkarken, mikroskobik subinguinal yaklaşımda bu oran \%1'ler seviyesine kadar düşebilmektedir. ${ }^{[9]}$ Literatürde, nüks varikosel yönetimi ve bu durumda uygulanacak cerrahi yöntemlerle ilgili yayın sayısı sınırlıdır. Bu çalışmada, nüks varikosel nedeniyle mikrocerrahi varikoselektomi (NMCV) yapılan hastaların verileri ile ilk defa tanı konulmuş ve primer MCV (PMCV) yapılan hastaların verilerinin karşılaştırılması amaçlanmıştır.

\section{GEREÇ-YÖNTEM}

Kliniğimizde, Kasım 2014 - Mayıs 2017 tarihleri arasında nüks varikosel nedeniyle NMCV yapılan 15 hasta ve kontrol grubu olarak da PMCV uygulanan 45 hastanın verileri retrospektif olarak incelendi. Çalışmaya sol Grade 3 varikosel nedeniyle subinguinal PMCV veya NMCV yapılan hastaların verileri dahil edildi. Hastaların yaş, ameliyat öncesi ve sonrası semen analizleri, komplikasyon oranları karşılaştırıldı. İstatistiksel analizler, SPSS for Windows Version 22 kullanılarak yapıldı (SPSS, Chicago, IL, USA). Çalışmada, NMCV grubu verilerinin değerlendirilmesi
Wilcoxon testi ile, PMCV verilerinin değerlendirilmesi ise Paired Sample T testi ile yapılırken, iki grubun verilerinin karşılaştırılması için Independent Sample T testi kullanıldı; $\mathrm{p}<0,05$ değeri istatistiksel olarak anlamlı kabul edildi.

\section{BULGULAR}

Çalışmaya alınan hastaların yaş ortalaması PMCV grubunda 30 (22-48) iken NMCV grubunda 31,2 (25-42) idi $(\mathrm{p}>0,05)$. PMCV grubunda $39(\% 86,7)$ hastaya infertilite nedeniyle ve $6(\% 13,3)$ hastaya ağrı nedeniyle cerrahi uygulanırken, bu oranlar NMCV grubunda sırasıyla $10(\% 66,7)$ ve $5(\% 33,3)$ hasta olarak bulundu. Hastalar komplikasyon açısından değerlendirildiğinde, ameliyatlar sonrasında her iki grupta da herhangi bir komplikasyonun gelişmediği gözlendi. Primer ve nüks gruptaki operasyon öncesi semen parametreleri karşılaştırıldığında, değerler arasında istatistiksel olarak anlamlı bir fark bulunmadı (Tablo 2). PMCV yapılan hastaların operasyon öncesi ve sonrası semen parametreleri değerlendirildiğinde, volüm ve morfoloji açısından anlamlı bir fark olmadığı, konsantrasyon ve motilite açısından istatistiksel olarak anlamlı iyileşme olduğu gözlendi (Tablo 3). NMCV yapılan hastaların

Tablo 1. Varikosel tedavisinde kullanılan tekniklerin nüks oranları (EAU kılavuzundan) ${ }^{[8]}$

\begin{tabular}{lc}
\hline Tedavï Yöntemi & Nüks \% \\
\hline Antegrad skleroterapi & 9 \\
Retrograd skleroterapi & 9,8 \\
Retrograd embolizasyon & $3,8-10$ \\
Inguinal yaklaşım & 13,3 \\
Yüksek ligasyon & 29 \\
Mikrocerrahi inguinal veya subinguinal & $0,8-4$ \\
Laparoskopi & $3-7$ \\
\hline
\end{tabular}

Tablo 2. Operasyon öncesi ve sonrası primer ve nüks gruplarında semen parametrelerinin karşılaştırılması

\begin{tabular}{|c|c|c|c|c|}
\hline \multirow{5}{*}{ Operasyon öncesi } & & Primer & Nüks & $p$ \\
\hline & Volüm (mL) & 2,48 & 2,31 & 0,489 \\
\hline & Konsantrasyon (milyon/mL) & 28,3 & 25,7 & 0,921 \\
\hline & Motilite (\%) & 25,4 & 21,5 & 0,699 \\
\hline & Morfoloji (Kruger) (\%) & 2,53 & 2,75 & 0,592 \\
\hline \multirow{4}{*}{ Operasyon sonrası } & Volüm (mL) & 2,2 & 2,23 & 0,808 \\
\hline & Konsantrasyon (milyon/mL) & 29 & 40 & 0,745 \\
\hline & Motilite (\%) & 30,4 & 32,2 & 0,758 \\
\hline & Morfoloji (Kruger) (\%) & 3 & 3 & 1,000 \\
\hline
\end{tabular}


Tablo 3. Primer varikoselektomi ve nüks varikoselektomi yapılan hastaların operasyon öncesi ve sonrası ortalama semen parametrelerinin kendi aralarında karşılaştırılması

\begin{tabular}{|c|c|c|c|c|}
\hline \multirow{5}{*}{$\begin{array}{l}\text { Primer } \\
\text { varikoselektomi } \\
(n=45)\end{array}$} & & Operasyon öncesi & Operasyon sonrası & $p$ \\
\hline & Volüm (mL) & 2,4 & 2,2 & 0,234 \\
\hline & Konsantrasyon (milyon/mL) & 28,3 & 29 & 0,020 \\
\hline & Motilite (\%) & 25,4 & 30,4 & 0,049 \\
\hline & Morfoloji (Kruger) (\%) & 2,5 & 3 & 0,051 \\
\hline \multirow{4}{*}{$\begin{array}{l}\text { Nüks varikoselektomi } \\
(n=15)\end{array}$} & Volüm (mL) & 2,31 & 2,23 & 0,719 \\
\hline & Konsantrasyon (milyon $/ \mathrm{mL}$ ) & 25,7 & 40 & 0,109 \\
\hline & Motilite (\%) & 21,5 & 32,2 & 0,045 \\
\hline & Morfoloji (Kruger) (\%) & 2,75 & 3 & 0,429 \\
\hline
\end{tabular}

operasyon öncesi ve sonrası semen parametreleri değerlendirildiğinde ise volüm, konsantrasyon ve morfoloji açısından anlamlı bir fark olmadığı, motilite açısından istatistiksel olarak anlamlı bir iyileşme olduğu gözlendi (Tablo 3).

\section{TARTISTMA}

İnfertil erkeklerde uygulanan en sık cerrahi işlem varikoselektomidir. Varikosel cerrahisinde hedef, spermatik korddaki lenfatik damarları ve arteri koruyarak, internal spermatik ven ve eksternal spermatik ven dallarını bağlamaktır.

Varikoselin radyolojik yöntemle tedavisinde internal spermatik venin embolizasyonu veya skleroterapi, femoral ven üzerinde gerçekleştirilen küçük bir insizyon ile gerçekleştirilir. Küçük kollateral venlerin oklüzyonunun mümkün olmaması nedeniyle, bu yöntemde nüks oranları \%4-11 arasında bildirilmiştir. ${ }^{[10,11]}$ Varikosel tedavisinde laparoskopik yöntem de kullanılmasına rağmen, eksternal spermatik venin görüntülenememesi nedeniyle bu yaklaşımda da nüks oranları yüksektir. ${ }^{[12]}$

İnguinal ve subinguinal mikrocerrahi teknikte, arter ve lenfatiklerin korunmasına yardımcı olarak bunlar dışındaki vasküler yapılar daha açık ortaya konulabildiği için, bu yöntemler nüks ve komplikasyonların daha az gözlendiği yöntemlerdir. ${ }^{[13,14]}$ Yapılan çok sayıda yayında, aynı cerrahi bölgeden yapılan (inguinal veya subinguinal) MCV'nin nüks oranlarının, konvansiyonel yöntemlere göre belirgin şekilde daha düşük olduğu rapor edilmiştir. ${ }^{[15]}$

Küçük internal spermatik ven dallarının görülememesi ve bu nedenle bağlanamaması, varikosel tedavisinde en önemli nüks nedenidir ve bu nedenle mikroskop veya optik büyüteç kullanılmadan yapılan konvansiyonel varikoselektomide nüks oranı daha fazla görülmektedir. ${ }^{[16,17]}$ Yapılan araştırmalarda, ideale en yakın cerrahi yöntemin optik büyüteç kullanılan inguinal veya subinguinal varikoselektomi olduğu belirtilmiştir. ${ }^{[18]}$ Bununla birlikte, daha distalde daha fazla ven ligasyonu, daha fazla ve küçük çapta arter dalı bulunması nedeniyle, daha yüksek arter yaralanma riski ve mikrocerrahiye daha fazla deneyim gerektirmesi subinguinal yöntemin dezavantajı olarak bildirilmektedir. ${ }^{[17]}$

Bütün bu veriler dikkate alındığında, ilk defa tanı konulmuş varikosel hastalarında MCV'nin diğer yöntemlere göre avantajlarının daha fazla olduğu artık tartışmasız bir gerçek olmasına rağmen, bu makalenin konusu olan nüks varikosellerdeki yaklaşımın ne olması gerektiği ile ilgili yayınlar kısıtlıdır. Bu çalışmadan elde edilen veriler ışı̆̆ında, aslında nüks varikosel cerrahisinin de primer varikoselde olduğu gibi aynı yaklaşımla yani mikrocerrahi yöntemle yapılmasının, hastalar açısından daha yüz güldürücü sonuçlar sağlayabileceği anlaşılmaktadır.

\section{SONUC}

Literatüre ve kılavuzlara göre, varikosel tedavisinde en düşük nüks oranına sahip yöntem olan mikrocerrahi varikoselektomi, nüks varikosel cerrahisinde de altın standart yöntem olabilir. Bu sonuçları doğrulamak için daha geniş çaplı seriler içeren çalışmalara ihtiyaç vardır.

\section{KAYNAKLAR}

1. Kendirci M, Miroğlu C. Varikosel patofizyolojisi. İçinde: Kadıŏlu A, Çayan S, Semerci B ve ark., editörler. Erkek Reproduktif Sistem Hastalıkları ve Tedavisi. İstanbul: Türk Androloji Derneği yayını; 2004. s.427-46.

2. Gorelick JI, Goldstein M. Loss of fertility in men with varicocele. Fertil Steril 1993;59:613-6.

3. World Health Organization. The influence of varicocele on parameters of fertility in a large group of men presenting to infertility clinics. Fertil Steril 1992;57:1289-93.

4. Cayan S, Lee D, Black LD, et al. Response to varicocelectomy in oligospermic men with and without defined genetic infertility. Urology 2001;57:530-5.

5. Belli L, Arrondello C, Antronaco R, et al. Venography of postoperative recurrence of symptomatic varicocele in males. Radiol Med 1998;95:470-3. 
6. Lee JW, Paick JS, Kim SW. Microsurgical subinguinal varicocelectomy: comparison of pediatric and adult patients. Korean J Urol 2008;49:1029-34. doi: 10.4111/kju.2008.49.11.1029

7. Al-Kandari AM, Shabaan H, Ibrahim HM, Elshebiny YH, Shokeir AA. Comparison of outcomes of different varicocelectomy techniques: open inguinal, laparoscopic, and subinguinal microscopic varicocelectomy: a randomized clinical trial. Urology 2007;69:417-20. doi: 10.1016/j.urology.2007.01.057

8. Dohle GR, Colpi GM, Hargreave TB, Papp GK, Jungwirth A, Weidner W; EAU Working Group on Male Infertility. EAU guidelines on male infertility. Eur Urol 2005;48:703-11. doi: 10.1016/j.eururo.2005.06.002

9. Cayan S, Kadioglu TC, Tefekli A, Kadioglu A, Tellaloglu S. Comparison of results and complications of high ligation surgery and microsurgical high inguinal varicocelectomy in the treatment of varicocele. Urology 2000;55:750-4.

10. Weissbach L, Thelen M, Adolphs HD. Treatment of idiopathic varicoceles by transfemoral vein occlusion. J Urol 1981;126:3546.

11. Ferguson JM, Gillespie IN, Chalmers N, et al. Percutaneous varicocele embolization in the treatment of infertility. $\mathrm{Br} \mathrm{J}$ Radiol 1995;68:700-3. doi: 10.1259/0007-1285-68-811-700

12. Oktar T, Ahmedov İ, Kadığlu A. Varikosel tedavisi. İçinde: Kadıŏlu A, Çayan S, Semerci B ve ark., editörler. Erkek Reprodüktif Sistem Hastalıkları ve Tedavisi. İstanbul: Türk Androloji Derneği yayını; 2004. s.463-72.
13. Marmar JL, DeBenedictis TJ, Praiss D. The management of varicoceles by microdissection of the spermatic cord at the external inguinal ring. Fertil Steril 1985;43:583-8.

14. Goldstein M, Gilbert BR, Dicker AP, Dwosh J, Gnecco C. Microsurgical inguinal varicocelectomy with delivery of the testis: an artery and lymphatic sparing technique. J Urol 1992;148:180811.

15. Hopps CV, Lemer ML, Schlegel PN, Goldstein M. Intraoperative varicocele anatomy: a microscopic study of the inguinal versus subinguinal approach. J Urol 2003;170(6 Pt 1):2366-70.

16. Goldstein M. Surgical management of male infertility. In: Wein AJ, Kavoussi LR, Novick AC, Partin AW, Peters CA, editors. Campbell-Walsh urology, Vol 1, 10th ed. Philadelphia, PA: Elsevier Saunders; 2011. p.648-87.

17. Grober ED, Chan PT, Zini A, Goldstein M. Microsurgical treatment of persistent or recurrent varicocele. Fertil Steril 2004;82:718-22. doi: 10.1016/j.fertnstert.2004.03.028

18. Cayan S, Shavakhabov S, Kadioğlu A. Treatment of palpable varicocele in infertile men: a meta-analysis to define the best technique. J Androl 2009;30:33-40. doi: 10.2164/ jandrol.108.005967 